\title{
A Study on The Safety Measures Against Fire Through An ESS Fire Analysis
}

\author{
Dong-Seung Back* and Kyung-Bum Lim** \\ *Department of Safety Education Graduate School of Education, Hanseo University, Chungcheognam-do, \\ 31962, Korea. \\ **Department of Electrical Engineering, Daejeon Institute of Science and Technology, \\ Daejeon, 35408, Korea. \\ ${ }^{* *}$ Corresponding author. Tel.: +82-10-3630-8573; Email address: kblim@ dst.ac.kr
}

Article History:Received:11 november 2020; Accepted: 27 December 2020; Published online: 5 April 2021

\begin{abstract}
Due to the increase in the frequency of fires due to the mass distribution of energy storage devices, following the introduction and operation of eco-friendly power generation facilities around the world, there is an urgent need to analyze the causes of such fires and to devise countermeasures against them. By analyzing the occurrence of ESS fires and reviewing the definition of ESS terminology, we intend to suggest some safety measures against ESS fires by understanding the related facilities and analyzing the causes. We would also like to propose new measures to prevent the spread of ESS fires. ESS fires occur most frequently during the discharge standby period after charging is completed in connected solar and wind power facilities. In addition, when we investigated the problems with the batteries, PCS manufacturing, ESS design, installation and construction, and the factors related to their usage and operation, we found such causes of fire as battery system defects, unsatisfactory protection systems against electrical shock, improper operations and environmental management, careless installations, and a lack of ESS integrated management systems. Therefore, a new approach is needed through the application of new technologies and safety measures including manufacturing standards, installation standards, operation and management standards, and firefighting standards for the purpose of ensuring the safety of these facilities and their operations, in order to prevent ESS fire accidents and the spread of fire.
\end{abstract}

Keywords: Energy storage system, ESS, ESS fire, Solar power system, Renewable energy.

\section{Introduction}

Recently, various types of power generation facilities have been introduced and are operated according to the wide application of eco-friendly energy[1-4]. Typically, among these facilities, the energy storage systems (ESS) are supplied in large quantities, and the frequency of fires related to these systems is on the rise. However, the research into this issue is insufficient[5-7]. The use of ESS has been rapidly increasing for the purpose of stabilizing the energy output, improving competitiveness, reducing the power bills in response to peak power demands, adjusting the frequency, and replacing emergency power generation in new renewable power generation systems. In the case of solar and wind power generation, which is a renewable form of energy, the ESS is necessary to store the generated electrical energy safely and to use the electricity efficiently when necessary, because a time difference between the power generation and its usage is inevitable, and the generated power is not of an even quality due to the high output fluctuations in terms of the voltage and frequency[8,9].

Therefore, in this study we intend to explain the principles of energy storage devices and analyze ESS fires that occurred in Korea and to conduct related research on fire prevention and safety measures, thereby contributing to the investigation of the causes of ESS-related fires and securing national safety through fire safety measures.

\section{Statistical analysis of ESS fire and definitions of the terms}

\subsection{ESS fire statistics}

2.1.1 Analysis of ESS fire occurrences

In analyzing the status of ESS fires, it is apparent that a total of 23 fires occurred, starting with one in the ESS connected to a wind power generation facility in August 2017 and more frequently from May 2018 until May 2019, as is shown in Table 1. Due to the use of ESS, 17 fires occurred in the ESS connecting solar and wind power, 4 fires in the ESS for demand management, and 2 fires occurred in the ESS used for frequency adjustment. In other words, 14 fires occurred during the discharge standby period after the charging was completed (in the pause period after the system was fully charged), 6 fires during the charging and discharging period, and 3 fires occurred during the installation or construction.

Table1 1 ESS fire accident situation

\begin{tabular}{ccccc}
\hline No & Data & Volume & Purpose & Type of accident \\
\hline 1 & 2017.08 .02 & 1.46 & Wind power & Installing \\
2 & 2018.05 .02 & 8.6 & Frequency & Repair and check
\end{tabular}

*Corresponding author: Kyung-Bum Lim

Department of Electrical Engineering, Daejeon Institute of Science and Technology,

Daejeon, 35408, Korea. Email address: kblim@dst.ac.kr 


\begin{tabular}{lcccc}
3 & 2018.06 .02 & 14 & Wind power & Repair and check \\
4 & 2018.06 .15 & 18.965 & Sunlight & Pausing after charging \\
5 & 2018.07 .12 & 2.99 & Sunlight & Pausing after charging \\
6 & 2018.07 .21 & 9.7 & Wind power & Pausing after charging \\
7 & 2018.07 .28 & 18 & Demand management & Installing \\
8 & 2018.09 .01 & 5.989 & Sunlight & Pausing after charging \\
9 & 2018.09 .07 & 6 & Sunlight & Installing \\
10 & 2018.09 .14 & 0.18 & Sunlight & Charging \\
11 & 2018.10 .18 & 17.7 & Frequency & Pausing after charging \\
12 & 2018.11 .12 & 3.66 & Sunlight & Pausing after charging \\
13 & 2018.11 .12 & 1.22 & Sunlight & Pausing after charging \\
14 & 2018.11 .21 & 4.16 & Sunlight & Pausing after charging \\
15 & 2018.11 .21 & 1.331 & Sunlight & Pausing after charging \\
16 & 2018.12 .17 & 9.316 & Demand management & Pausing after charging \\
17 & 2018.12 .22 & 2.662 & Sunlight & Pausing after charging \\
18 & 2019.01 .14 & 3.289 & Demand management & Pausing after charging \\
19 & 2019.01 .14 & 5.22 & Sunlight & Charging \\
20 & 2019.01 .15 & 2.496 & Sunlight & Pausing after charging \\
21 & 2019.01 .21 & 46.757 & Demand management & Pausing after charging \\
22 & 2019.05 .04 & 3.66 & Sunlight & Pausing after charging \\
23 & 2019.05 .26 & 1.027 & Sunlight & Pausing after charging \\
\hline
\end{tabular}

\subsection{Definition of the ESS terms}

\subsubsection{ESS(Energy Storage System)}

This refers to a system that stores the electrical energy produced in a facility in storage devices such as batteries, for the purpose of supplying that energy when it is needed. A device stores the electrical energy produced from other power sources, such as power systems, solar power, wind power, and renewable energy, in a battery for use when necessary. The ESS is composed of a PCS(Power Conversion System), PMS(Power Management System), and a BMS(Battery Management System) as shown in Figure 1[8-10].

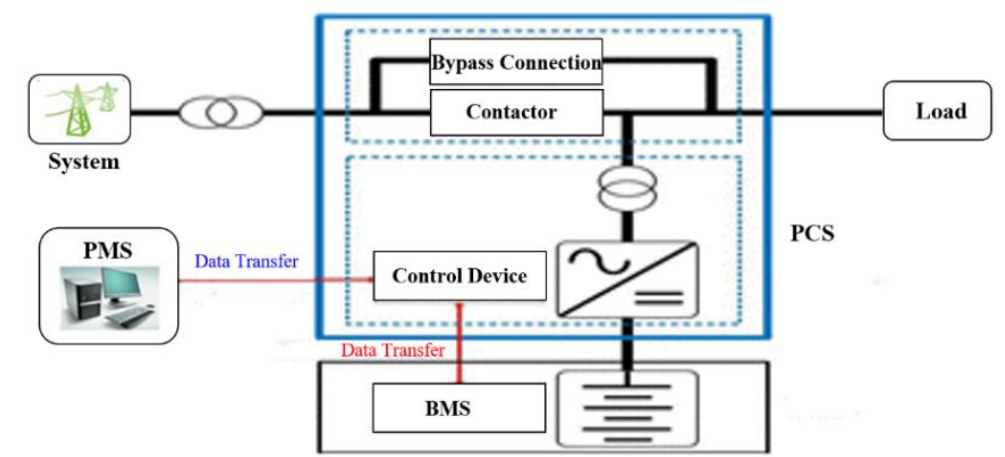

Figure 1 ESS configuration diagram

\subsubsection{BMS(Battery Management System)}

The Battery Management System, as shown in Figure 2, refers to a device that accurately balances the battery with the cell capacity, enabling all cells to be fully charged, and monitors the battery condition in order to control and protect the system and predict its lifespan to fully utilize the saved electrical energy and enable it to be used in the optimal conditions[11,12]. 


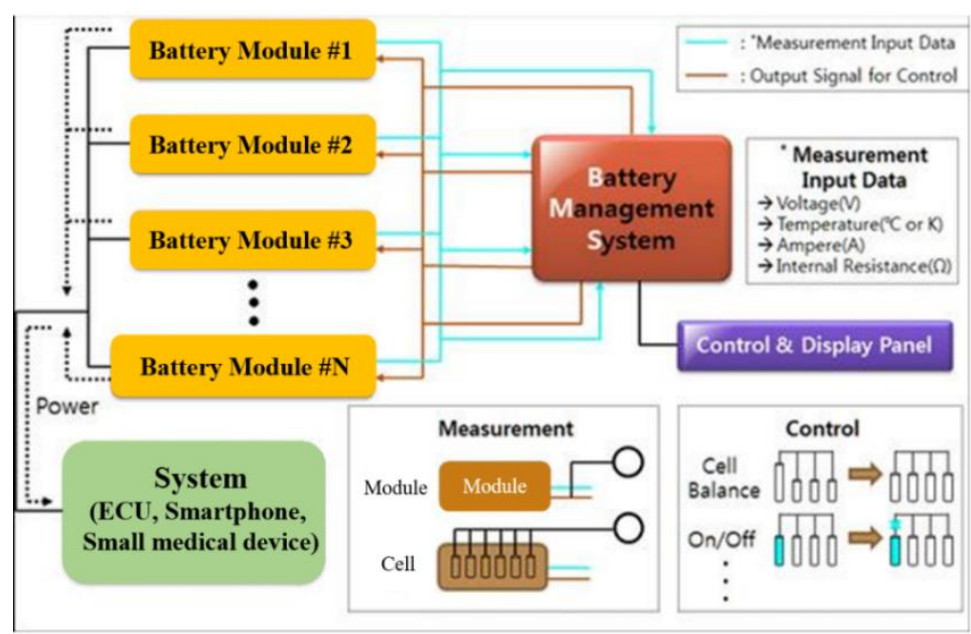

Figure 2 Battery Management System

\subsubsection{PCS(Power Conversion System)}

The Power Conversion System is the system that converts the characteristics(frequency, voltage, AC/DC) of the electricity for the input and storage of power within an ESS, or for its release to another system, as shown in Figure 3. The PCS plays a role in converting power and operates in a manner similar to the inverter in a photovoltaic system. It is a device that can both convert the direct current electricity stored from a battery into an alternating current to supply electricity directly to an alternating current load, and can convert the alternating current electricity from a power system into a direct current to store the electricity in a battery. Generally, it is presented as s PCS[13].

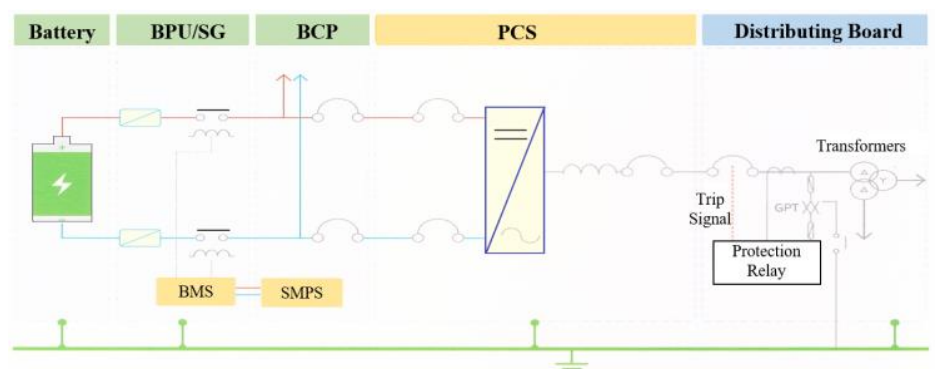

Figure 3 Power conversion system

\subsubsection{EMS(Energy Management System)}

Figure 4 refers to an enterprise-wide Energy Management System that is designed with the goal of improving energy efficiency and promoting the management system in a systematic and continuous manner, according to certain specified procedures and techniques. IT(Information Communication Technology) software is applied to manage and optimize the energy usage in factories and homes. In this way, companies can cut costs, and countries can cut their energy consumption and greenhouse gas emissions[14,15].
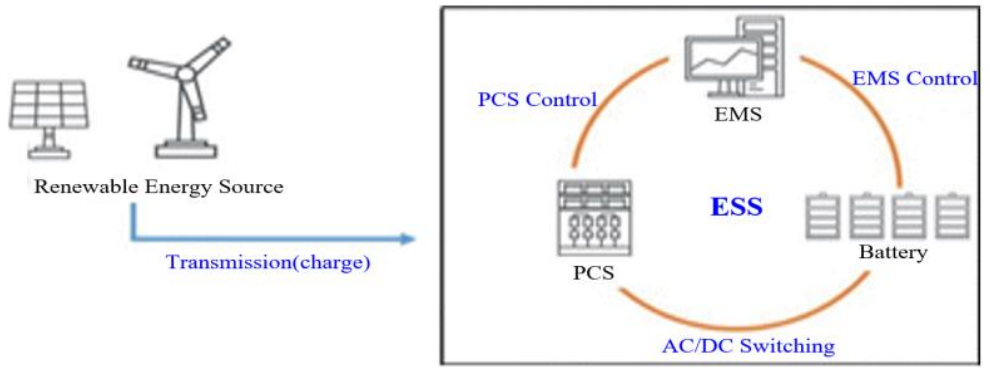

Figure 4 Energy Management system

\section{Analysis of the causes of ESS fire and safety measures}

3.1 Analysis of the causes of ESS accidental fires

The results of an investigation into the causes of ESS fires, included in Table 1, are as follows. 


\subsubsection{Unsatisfactory battery protection systems}

We found that an electric shock (overvoltage/overcurrent), as an electrically hazardous factor, results from the ground and short circuits and enters the battery system, the rack fuse or the battery protection system, along with a failure to quickly shut off the short circuit current, which can result in the explosion of a direct current contactor that has a degraded insulation performance, while also creating a secondary short circuit at the bus bar within the battery protection device and at the enclosure of the battery protection device, and may generate a fire in the battery.

\subsubsection{Unsatisfactory management of the operational environment}

In the case of the ESS installed in mountainous or coastal areas, we found that they are often operated in a poor environment prone to condensation, due to large daily temperature changes and large amounts of dust, and that dust was deposited in the ESS due to the repeated generation and drying of condensation inside the battery module, which may have resulted in damage to the insulation in the ground between the cell and the module enclosure, thereby resulting in a fire.

\subsubsection{Careless installation}

It was revealed that a fire can occur when the ESS is installed carelessly, such as poor storage of the batteries or faulty wiring.

\subsubsection{Unsatisfactory integrated protection and management system}

The fact that the ESS is not designed and protected as an integrated system and the fact that the EMS, PMS, and BMS are made by different parties and are not organically connected and operated by the SI company were found to be problematic factors in preventing accidents, as well as in preventing a fire from spreading to the entire system once it has begun and investigating the cause of an accident smoothly.

\subsection{ESS safety measures}

The safety measures of the ESS should be comprehensively constructed based on overseas standards and the results of accident investigations, to ensure safety by reflecting the characteristics of the ESS. Comprehensive safety measures are required, including improving the safety standards and management systems for fire prevention, preparing firefighting standards to cope with such fires and minimize damage, and implementing safety measures for the existing facilities. Table 2 shows the safety measures that should be taken to prevent ESS accidental fires.

Table1 2 Safety measures for ESS accidents

\begin{tabular}{cl}
\hline Division & Main content \\
\hline Manufacturing & - Introduced the world's first international standard for ESS system safety \\
standards & - Certification of major parts such as batteries and PCS \\
& - Battery protection device performance and integrated control protocol \\
& regulations and detailed standards \\
Installation & - Mandatory electrical protection device facilities \\
standard & - Emergency stop and monitoring system in case of emergency \\
& - ESS work procedure for each group \\
Operation & - Strict management of temperature, humidity, dust, etc. \\
management & - Reduction of legal inspection period \\
& - Penalty regulations for arbitrary changes in facilities \\
Fire fighting & - Designation of specific fire fighting targets \\
standards & - Preparation of fire safety standards specialized for ESS \\
\end{tabular}

\subsection{Application of a fire prevention sheet for preventing the spread of ESS fires}

The problem with ESS fires is that they not only burn down within a few hours of their occurrence but also are difficult to extinguish in the early stages. Since it is not easy to extinguish such a fire because the smoke generated contains toxic substances, comprehensive safety measures are definitely needed to prevent the spread of the fire. Therefore, we have investigated the applicability of fire prevention sheets to prevent the spread of an ESS fire[16,17].

\subsubsection{Flame-retardant mechanism for char formation}


It is necessary to apply intumescent refractory materials and adhesives to prevent the flames from spreading to other materials throughout the facility in the case of a fire[18]. UR, DCDA, ML, and M80S are thermosetting resins, and these materials can be applied to provide hardness to the char when it is formed using a phosphate, as shown in Table 3.

Table1 3 Flame retardant mechanism for char formation

\begin{tabular}{cccc}
\hline Flame retardant mechanism & Melamine & Melamine cyanurate & Melamine \\
\hline Affect Dhosphate \\
Heat Sink & $\mathrm{Y}$ & $\mathrm{Y}$ & $\mathrm{Y}$ \\
Inert Gases & $\mathrm{Y}$ & $\mathrm{Y}$ & $\mathrm{Y}$ \\
Char Formation & $\mathrm{Y}$ & $\mathrm{Y}$ & $\mathrm{Y}$ \\
Intumescence & & $\mathrm{Y}$ & $\mathrm{Y}$ \\
Heat Insulation & & \\
Heat Transfer (Dripping) & $\mathrm{Y}$ & \\
\hline
\end{tabular}

\subsubsection{Composition of the components of a fire prevention sheet}

Fire protection sheets used for preventing a fire from spreading have been manufactured using DT(Diammonium phosphate) and M80S(Methylolmelamine) as the intumescent components. Expanded graphite was added to complement the intumescence and insulation, while urethane was utilized to secure the applicability and flexibility. Table 4 shows the composition of each type of component.

Table1 4 Components and performance classification by type

\begin{tabular}{|c|c|c|c|}
\hline Division & Type A & Type B & Type C \\
\hline Phosphate & $\mathrm{O}$ & $\mathrm{O}$ & $\mathrm{O}$ \\
\hline Organic nitrogen compounds & $\mathrm{O}$ & $\mathrm{O}$ & $\mathrm{O}$ \\
\hline Polymer stabilizer & & $\mathrm{O}$ & $\mathrm{O}$ \\
\hline Expanded graphite & & & $\mathrm{O}$ \\
\hline Suppressant & & & $\mathrm{O}$ \\
\hline Polyol & & & $\mathrm{O}$ \\
\hline Isocyanate & & & $\mathrm{O}$ \\
\hline flexibility & $x$ & $\triangle$ & $\mathrm{O}$ \\
\hline Degree of expansion[mm/1mm] & 35 & 22 & 21 \\
\hline
\end{tabular}

3.3.3 Performance evaluation of the fire prevention sheet

A performance evaluation was carried out for the application of the fire prevention sheets to prevent the spread of fire.

The results of a measurement of the total heat discharge, discharge rate, ignition time, and extinguishing time are shown in Table 5, with four samples stacked using a cone calorimeter in accordance with the KS F ISO 5660-1 test method for flame-resistant materials.

Table1 5 Flame retardant evaluation by type

\begin{tabular}{cccc}
\hline Division & Type $\mathbf{A}$ & Type B & Type C \\
\hline Total heat release[MJ/m2] & 2.7 & 5.8 & 4.9 \\
Heat release rate[kW/m2] & 94.6 & 91.5 & 89.1 \\
\hline
\end{tabular}




$\begin{array}{cccc}\text { Ignition time } & 21 & 24 & 26 \\ \text { Digestion time } & 72 & 70 & 57 \\ \text { Gas hazard [min] } & 9.4 & 9.6 & 14.1 \\ \text { Flame retardant } & & \text { Flame retardant grade 2 }\end{array}$

The most important factor is the total heat discharge. If it is less than $8 \mathrm{MJ}$ after being burned for 5 minutes, the material is recognized to be flame-resistant; while if it is less than $8 \mathrm{MJ}$ after being burned for 10 minutes, the material can be recognized as quasi-noncombustible.

When the above tests were evaluated, the materials showed the greatest differences in terms of water resistance and flexibility, although no problems were found regarding intumescence or flame retardancy. Type $\mathrm{C}$ was the best material and it was selected as the basic composition for further R\&D on preventing the spread of additional ESS fires.

\section{Conclusions}

The results of the analysis of the ESS fires that have occurred in Korea and the consideration of various the fire prevention measures and safety measures are as follows.

(1) Safety measures need to be prepared for the manufacturing standards, installation standards, operation and management standards, and the firefighting standards for the purpose of ensuring the safety of facilities and operations against accidental ESS fires.

(2) A new approach is needed, including the application of new technologies such as fire safety measures for storage facilities using intumescent pads to prevent the spread of fire.

\section{Acknowledgements}

This paper was studied by the research project of the Hanseo University Industry-Academic Cooperation Foundation in 2020.

\section{References}

1. Song S, Ai H, Zhu W, Qiu F, Wang Y, Zhou J. Eco-friendly electrospun nanofibrous membranes with high thermal energy capacity and improved thermal transfer efficiency. RENEWABLE ENERGY. 2020;148:504-511.

2. Olabi AG, Mahmoud M, Soudan B, Wilberforce T, Ramadan M. Geothermal based hybrid energy systems, toward eco-friendly energy approaches. RENEWABLE ENERGY. 2020;147:2003-2012.

3. Chandrasekaran K, Simon SP. Development of sustainable energy on generation system leads to ecofriendly society. Sustainable Cities and Society. 2013;8:1-15.

4. Koga H, Tonomura H, Nogi M, Suganuma K, Nishina Y. Fast, scalable, and eco-friendly fabrication of an energy storage paper electrode. GREEN CHEMISTRY. 2016;18(4):1117-1124.

5. Caliano M, Bianco N, Graditi G, Mongibello L. Design optimization and sensitivity analysis of a biomass-fired combined cooling, heating and power system with thermal energy storage systems. Energy conversion and management. 2017;149:631-645.

6. Zhai R, Li C, Chen Y, Yang Y, Patchigolla K, Oakey JE. Life cycle assessment of solar aided coal-fired power system with and without heat storage. Energy conversion and management. 2016;111:453-465.

7. Blanc-Vannet P, Jallais S, Fuster B, Fouillen F, Halm D, van Eekelen T, et al. Fire tests carried out in FCH JU Firecomp project, recommendations and application to safety of gas storage systems. International journal of hydrogen energy. 2019;144(17):9100-9109.

8. Rogers P. Responses to Energy Storage Systems. FIRE ENGINEERING. 2015;168(6):79-82.

9. Sternberg A, Bardow A, Power-to-What? - Environmental assessment of energy storage systems. ENERGY \& ENVIRONMENTAL SCIENCE. 2015;8(2):389-400.

10. Wang Q, choi SS. The Design of Battery Energy Storage System in a Unified Power-Flow Control Scheme. IEEE TRANSACTIONS ON POWER DELIVERY. 2008;23(2):1015-1024.

11. Xu L, Wang J, Chen Q. Kalman filtering state of charge estimation for battery management system based on a stochastic fuzzy neural network battery model. Energy Conversion and Management. 2011;53(1):33-39.

12. Kumar S, Ikkurti HP. Power Electronic Interface for Energy Management in Battery Ultracapacitor Hybrid Energy Storage System. ELECTRIC POWER COMPONENTS AND SYSTEMS. 2013;41(11):1059-1074. 
13. Johnson GA. Power Conversion System Evaluation for the Next Generation Nuclear Plant. Nuclear Technology. 2011;175(2):371-387.

14. Dieterle W, Kochs HD, Dittmar E. LAN Based Data Communication in Modern Energy Management Systems (EMS). IEEE Transactions on Power Systems. 1996;11(1):469-474.

15. Moradi MH, Hajinazari M, Jamasb S, Paripour M. An energy management system (EMS) strategy for combined heat and power (CHP) systems based on a hybrid optimization method employing fuzzy programming. Energy. 2012;49:86-101.

16. Baldassarra CF. Energy and New Fire Protection Challenges: Experts discuss emerging alternative energy sources and their impact on fire protection engineers, regulators, owners and consumers. FIRE PROTECTION ENGINEERING. 2007;36:10-22.

17. Connor B. Emerging Technologies NFPA 855 and ESS. NFPA JOURNAL. 2019;113(3):82.

18. Cusack P. Slowing the spread of cable insulation fires: The differences between new and old cable insulation materials. Fire prevention. 1998;308:32-35. 